\title{
POSTNATAL WEIGHT CHANGES IN VERY LOW BIRTH WEIGHT (VLBW) INFANTS - COMPARISON WITH INTRAUTERINE AND POSTNATAL GROWTH GRIDS
}

\author{
K. Cardoso ${ }^{1}$, C. Espírito Santo ${ }^{1}$, A. Graça ${ }^{2,3}$
}

\author{
${ }^{1}$ Pediatrics, ${ }^{2}$ Neonatology, Hospital de Santa Maria - Centro Hospitalar de Lisboa Norte, EPE, ${ }^{3}$ Pediatrics, \\ Faculdade de Medicina - Universidade de Lisboa, Lisbon, Portugal
}

Background and objectives: The better providers understand growth of premature infants, more appropriate interventions can be developed to help these children to grow and develop. Controversy still exists whether growth of premature infants should be compared with intrauterine or longitudinal postnatal growth curves. We aimed to define the postnatal growth of premature infants and compare it with reference growth curves.

Methods: We studied a prospective cohort of VLBW infants. Infants whose birth weight was $<10^{\text {th }}$ centile, major neurological lesions and necrotizing enterocolitis $\geq$ IIa were excluded. Weight was measured at five time points until 44 weeks postnatal age.Multiple comparisons were made between our postnatal weight gain and Ehrankranz's adequate for gestational age and Fenton's $50^{\text {th }}$ centile weight growth curves, using Wilcoxon's test after Bonferroni's adjustment for multiple comparisons.

Results: We studied 88 infants with a mean GA of 28,6 weeks and a mean birth weight of $1085 \mathrm{~g}$. Postnatal weight gain was statistically different from Fenton's $50^{\text {th }}$ centile in all time points $(p \leq 0,003)$. There was no difference when we compare our postnatal weigh growth with Ehrenkranz's curves except for infants with birth weight 701-900, 901-1100 and 1101-1300g, which had less weight at $13^{\text {th }}$ postnatal day.

Conclusions: Intrauterine growth curve were not appropriate for evaluation of postnatal weight gain of our cohort and confirms impression given by most authors that an adverse extrauterine environment prevents catch-up growth. Extrauterine postnatal curves proved to be more realistic and suitable to evaluate weight gain of premature infants. 